\title{
Airborne Nanoparticles Filtration by Means of Cellulose Nanofibril Based Materials
}

\author{
Laura Alexandrescu1, Kristin Syverud ${ }^{2,3}$, Alessia Nicosia ${ }^{4}$, Gianni Santachiara4, \\ Alberto Fabrizi ${ }^{5}$, Franco Belosi ${ }^{4}$ \\ ${ }^{1}$ CASM, Politechnic University, Bucharest, Romania \\ ${ }^{2}$ Department of Chemical Engineering, Norwegian University of Science and Technology (NTNU), Trondheim, \\ Norway \\ ${ }^{3}$ PFI Paper and Fibre Research Institute, Trondheim, Norway \\ ${ }^{4}$ Institute of Atmospheric Sciences and Climate (ISAC-CNR), Bologna, Italy \\ ${ }^{5}$ Department of Management and Engineering, University of Padova, Vicenza, Italy \\ Email: f.belosi@isac.cnr.it
}

Received 28 September 2015; accepted 3 January 2016; published 6 January 2016

Copyright (C) 2016 by authors and Scientific Research Publishing Inc.

This work is licensed under the Creative Commons Attribution International License (CC BY).

http://creativecommons.org/licenses/by/4.0/

(c) (†) Open Access

\begin{abstract}
Nanoparticles in air are of particular concern for public health and employee exposure in workplaces. Therefore, it is very important to prepare effective filters for their removal. In this work filters were prepared from nanocellulose, i.e. cellulose nanofibrils (CNF). CNF was produced using two methods giving two different qualities of CNF. One quality had negative charges on the fibril surfaces while the other was neutral, and had in addition thinner fibrils compared to the other qualities. Filter samples were produced from water dispersions of CNF, by removal of the water by freeze drying. The performance of the CNF based filters was assessed and compared with filters based on synthetic polymer fibres. The ability to collect $\mathrm{NaCl}$ particles with a broad size distribution, ranging from nanometer to micrometer scale, was determined. CNF filters showed quality values comparable with the synthetic polymer based filters. Filters based on both the two CNF qualities had very good filtration efficiency for a given pressure drop across the filter.
\end{abstract}

\section{Keywords}

Air Filtration, Nanoparticles, Cellulose Nanofibrils

\section{Introduction}

Nanoparticles are particles with at least one dimension less than $100 \mathrm{~nm}$. As the concentrations of airborne na-

How to cite this paper: Alexandrescu, L., Syverud, K., Nicosia, A., Santachiara, G., Fabrizi, A. and Belosi, F. (2016) Airborne Nanoparticles Filtration by Means of Cellulose Nanofibril Based Materials. Journal of Biomaterials and Nanobiotechnology, 7, 29-36. http://dx.doi.org/10.4236/jbnb.2016.71004 
noparticles increase with the development of nanotechnology and other sources, concerns have arisen with respect to the potential negative impact on human health [1] [2]. Removal of such particles is thus of high importance. This can be done by filtration using effective filters. Filtration is one of the most commonly applied methods for aerosol sampling and air purification. Its application spreads across a wide range of disciplines, including respiratory protection, air purification of combustion effluents, processing of nuclear and hazardous materials, and clean rooms.

High performance filters are characterised by being able to collect particles of a broad size distribution. Large specific surface area of the fibres forming the filter is beneficial in this respect. At the same time, the air flow through the filter should not be hindered above a certain level, i.e. the pressure drop across the filter should be low. The procedures for testing and certifying air-purifying and particulate respirators in Europe are governed by European standards EN 143:2000 (Respiratory protective devices-Particle filters-Requirements, testing, marking). Nanocellulose is a group of isolated cellulosic materials with dimensions in the nanometer range, and comprises bacterial cellulose (BC), cellulose nanofibrils (CNF) and cellulose nanocrystals (CNC or whiskers). CNF have many advantageous properties concerning aerosol filtration, such as the high strength and high specific surface area. These properties make them interesting for filtration purposes. Several procedures for preparation of CNF from cellulose pulp exist. The simplest method is to fibrillate the cellulose fibres, used as raw material, using only mechanical forces. In another procedure, TEMPO-mediated oxidation using sodium hypochlorite as oxidant catalyzed with TEMPO (2,2,6,6-tetramethylpiperidine-1-oxy) is done prior to fibrillation [3]. In this method, aldehyde and carboxyl groups are introduced on the surfaces of the cellulose fibrils. TEMPO mediated oxidation facilitates the separation of the nanofibrils. This results in a dispersion of individualized nanofibrils, with widths of typically 3.5 to $20 \mathrm{~nm}$ [4] and length estimated to be between 0.2 and $2.2 \mu \mathrm{m}$ depending on oxidation and homogenization conditions [5] [6].

One of the challenges in the preparation of filters from CNF is the removal of water from the produced CNF dispersion. The individual fibrils tend to aggregate during drying, and numerous hydrogen bonds are formed resulting in compact structures. Such aggregation must be avoided when preparing filters.

In the present work the potential of using CNF for filtration purposes is explored. The CNF based filters have been prepared and used for air particle filtration. Tests were carried out with laboratory generated $\mathrm{NaCl}$ particles.

\section{Materials and Methods}

\subsection{Materials}

Production and characterization of the samples of CNF have been reported elsewhere [7] and are only summarized here. A never-dried bleached market kraft pulp was used in this study. This was an "Eucalyptus pulp" composed of 70\% "Eucalyptus nitens" and 30\% "Eucalyptus globules”. Two kinds of CNF were prepared and tested, with and without TEMPO mediated oxidation as pre-treatment [3].

\subsection{Methods}

\subsubsection{Filter Preparation}

The fibrillation was done by homogenization using a Rannie homogenizer operated at 1000 bar pressure. The CNF samples were collected after five passes through the homogenizer.

Hereafter, the sample produced through mechanical homogenization will be referred to as "mechanical”, and the one which was oxidized using sodium hypochlorite $\left(\mathrm{NaClO}_{2}\right)$ catalyzed with TEMPO will be referred to as “oxidized”. Preparation of CNF based filter samples was done in the following way: CNF dispersions of $0.1 \%$ to $0.3 \%$ solid content were poured into Petri dishes, corresponding to basis weights of $10 \mathrm{~g} \cdot \mathrm{m}^{-2}$. The solid content of the dispersion before freeze drying determines the density of the final filter sample. The samples were frozen at $-25^{\circ} \mathrm{C}$ and transferred to a vacuum dryer. Table 1 gives an overview of the CNF based filter samples.

By stirring the samples during the freezing procedure, the formation of large ice crystals was avoided, thus giving filters with more uniform pore sizes. By stirring, cracks due to unequal cooling throughout the sample structure were also avoided. Uneven pore size could still be observed between the fibrillar regions. Transmission electron microscopy observations were performed with a JEOL JEM 2000EX II TEM operating at $80 \mathrm{kV}$ (Figure 1). 


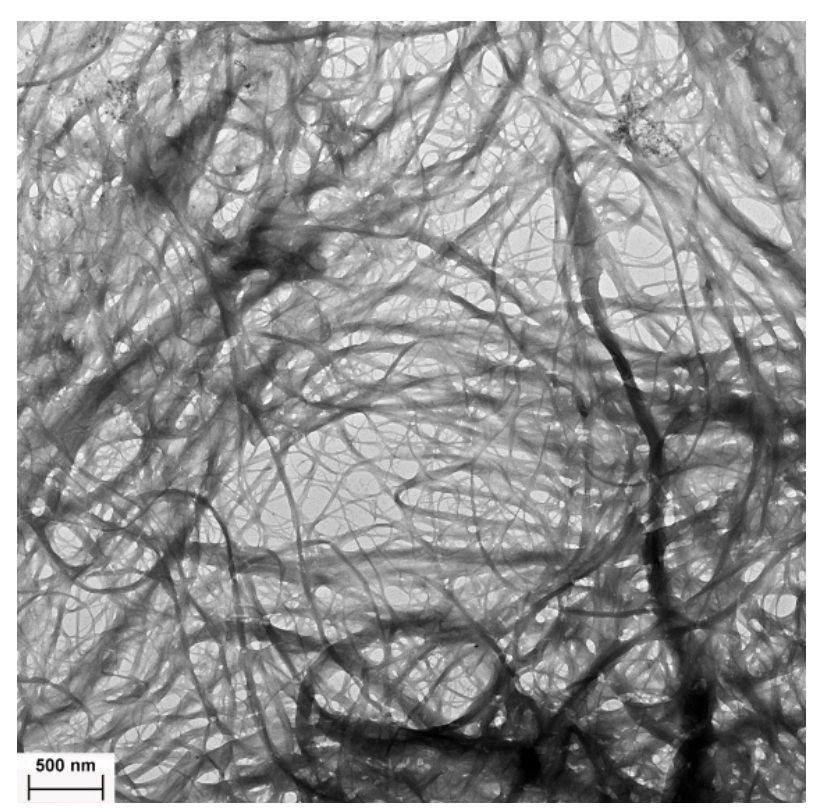

Figure 1. TEM image of $0.1 \%$ solid content CNF suspension. Left bar $500 \mathrm{~nm}$.

\begin{tabular}{ccc}
\multicolumn{2}{l}{ Table 1. CNF based filters. } \\
\hline Sample code & Pre-treatment & Solid content of initial suspension (\%) \\
\hline C1 & None & 0.1 \\
C2 & None & 0.2 \\
C3 & None & 0.3 \\
T1 & TEMPO & 0.1 \\
T2 & TEMPO & 0.2 \\
\hline
\end{tabular}

A drop of diluted nanofibril suspension was deposited onto a Formvar-coated copper grid and left to dry at room temperature. The samples were prepared for field emission gun environmental scanning electron microscopy (FEG-ESEM) investigations. Pieces of the assessed samples were mounted on aluminum stubs using double-sided adhesive carbon tapes. The specimens were observed uncoated using a FEI Quanta 200 ESEM operating in low vacuum mode, and micrographs were acquired with an accelerating voltage ranging between 5 and $20 \mathrm{kV}$.

\subsubsection{Filter Characterization}

The aerosol filtration efficiency of the CNF-based filters was assessed using the experimental set-up shown in Figure 2. The challenging particles were generated by nebulizing a $\mathrm{NaCl}$ solution $(0.4 \% \mathrm{w} / \mathrm{w})$ with a Collison atomizer [8].

The nebulized droplets were then dried by means of a silica gel column and the aerosol was diluted and sent to the tested filter. The upstream and downstream particle number concentrations were measured by means of a scanning mobility particle sizer (SMPS), including a long differential mobility analyser (Grimm Aerosol Technik, L-DMA 5400) and a condensation particle counter (Grimm Aerosol Technik, mod. 5.403).

Filtration efficiency was calculated in each test by measuring upstream-downstream-upstream particle number concentration successively. The upstream particle number concentration considered was the average of the two measurements. Most of the generated particles had size below $100 \mathrm{~nm}$ and around half of them below $30 \mathrm{~nm}$. The filtration face velocity for the proofs was set at $5.3 \mathrm{~cm} \cdot \mathrm{s}^{-1}$ to compare the CNF membrane performances with published data. The pressure drop across the filters were measured by means of a digital manometer (Testo 512 model), before and after each filtration test sessions, in order to evaluate filter clogging. 


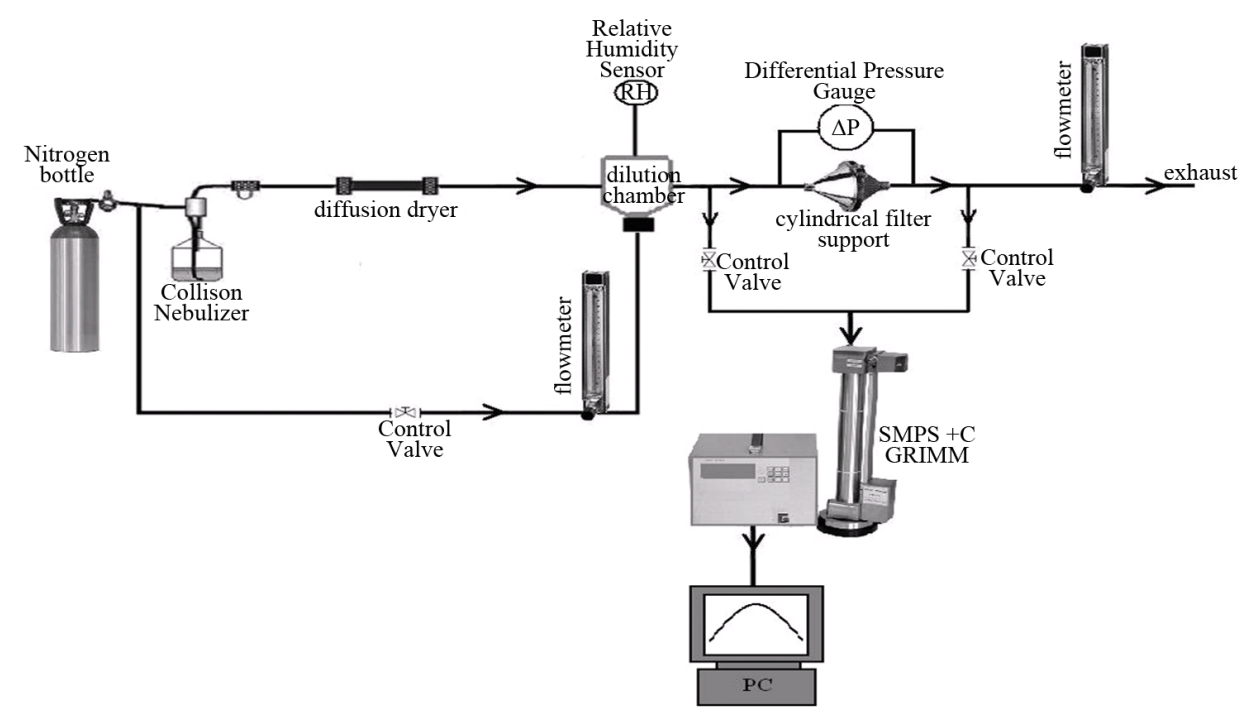

Figure 2. Experimental set-up.

\subsubsection{Quality Factor}

Filtration efficiency and pressure drop were both considered in the Quality Factor (QF) of the filter which is often used to evaluate the filtration performance of filters. QF is defined as [9]:

$$
\mathrm{QF}=-\frac{\ln (1-E)}{\Delta P}
$$

where $\Delta P$ is the pressure drop and $E$ is the filter collection efficiency. Filters that exhibit high filtration efficiency, at a low pressure drop, are the most desirable ones. Therefore, larger values of QF indicate better filter quality.

\section{Results and Discussion}

\subsection{Pressure Drop and Filtration Efficiency Measurements}

Filtration efficiency measurements could not be performed for samples C2, C3 and T2, due to too high pressure drop values. Therefore, only samples C1 and T1 were considered. The collection efficiency is shown in Figure 3. In the nanoparticle size range the oxidized sample $\mathrm{T} 1$ had higher filtration efficiency compared to the mechanical sample C1, at the same solid content. The Most Penetrating Particle Size (MPPS) was comparable for both samples (around $170 \mathrm{~nm}$ ). The T1 sample shows the higher QF value, but the efficiency at MPPS is lower than that for the $\mathrm{C} 1$ sample.

Table 2 shows an overview of pressure drop, collection efficiency and QF values of nanofibrous and multi-layer fibrous filters reported in literature. Only results for the best performing samples with a minimum of mixed sandwiched layers are reported. QF values reported in literature, at the face filtration velocity of $5.3 \mathrm{~cm}$ $\mathrm{s}^{-1}$, range between 0.01 and $0.02 \mathrm{~Pa}$. From Table 2 it can be observed that these values are comparable to those obtained with microfibrillated cellulose filters.

The filtration efficiencies of the CNF based filters are lower, but the pressure drop is also significantly lower, meaning that the filtration efficiency can be increased considerably by increasing the density of fibrils, and thus also the filtration efficiency.

\subsection{Model Comparison}

To assess the characteristics of CNF membrane as a potential new filtering material, a comparison was carried out between the theoretical and experimental behaviour of filters, made with $0.1 \%$ oxidized and mechanical CNF. There are several mechanisms by which particles can be filtered. They include interception, diffusion, impaction and electrostatic attraction [9]. 


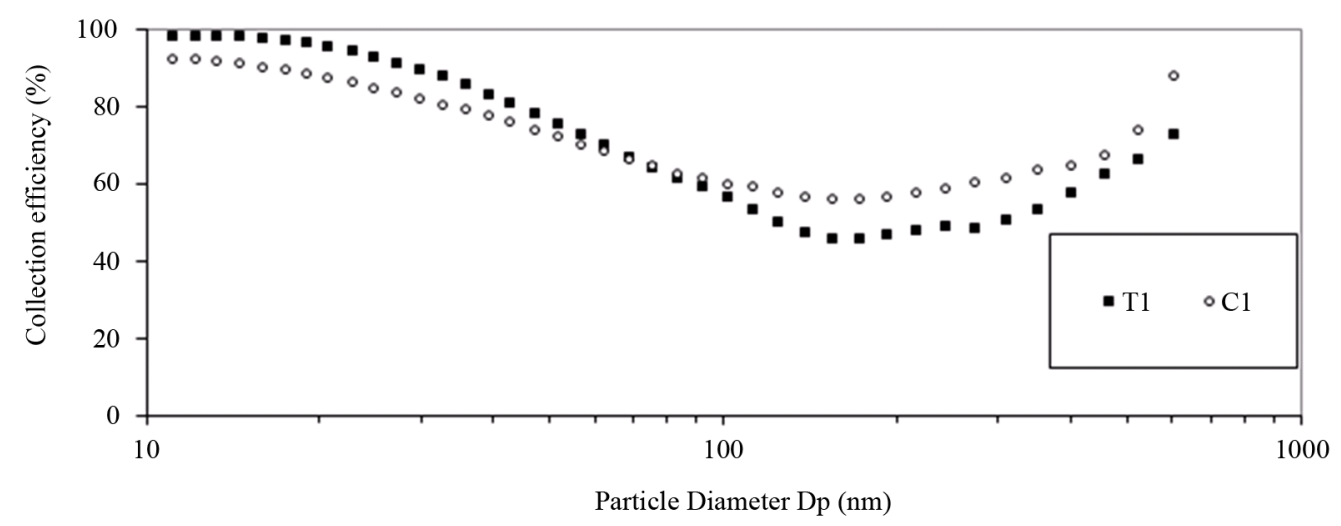

Figure 3. Collection efficiency of samples C1 and T1. Filtration face velocity $5.3 \mathrm{~cm} \cdot \mathrm{s}^{-1}$.

Table 2. Summary of filter quality factor from literature and the present work.

\begin{tabular}{|c|c|c|c|c|c|c|}
\hline Research & Filter name & Material & $\begin{array}{l}\text { Pressure } \\
\text { drop }\end{array}$ & $\begin{array}{c}\text { Efficiency } \\
(\%)\end{array}$ & $\begin{array}{l}\mathbf{Q F} \\
\left(\mathbf{P a}^{-1}\right)\end{array}$ & Note \\
\hline$[10]$ & PAN 15 & $\begin{array}{l}\text { Single layer of electrospun } \\
\text { polyacrylonitrile nanofiber mat } \\
\text { sandwiched between two } \\
\text { activated carbon fiber mats. }\end{array}$ & $98 \mathrm{~Pa}$ & $89.8 \%$ & 0.0233 & $\begin{array}{c}\text { Tested at } 5.3 \mathrm{~cm} \cdot \mathrm{s}^{-1} \text { with } \\
300 \mathrm{~nm} \text { polystyrene latex } \\
\text { particles. }\end{array}$ \\
\hline [11] & N9 & $\begin{array}{l}\text { Electrospun polyethylene oxide } \\
\text { nanofiber layer on microfiber } \\
\text { substrate. }\end{array}$ & $161 \mathrm{~Pa}$ & $85 \%{ }^{*}$ & $\square 0.0118^{*}$ & $\begin{array}{l}\text { Tested at } 5 \mathrm{~cm} \cdot \mathrm{s}^{-1} \text { with } \\
\mathrm{NaCl} \text { particles from } 50 \\
\text { to } 480 \mathrm{~nm} .\end{array}$ \\
\hline$[12]$ & $\mathrm{L}$ & $\begin{array}{l}\text { Electrospun nylon nanofiber } \\
\text { layer on microfiber substrate. }\end{array}$ & $62 \mathrm{~Pa}$ & $60 \%{ }^{*}$ & $0.0147^{*}$ & $\begin{array}{l}\text { Tested at } 5 \mathrm{~cm} \cdot \mathrm{s}^{-1} \text { with } \\
\mathrm{NaCl} \text { particles from } 50 \\
\text { to } 500 \mathrm{~nm} .\end{array}$ \\
\hline$[13]$ & A3 & $\begin{array}{l}\text { Nanoweb membrane obtained } \\
\text { by meltblowing technique from } \\
\text { polymers. }\end{array}$ & $119 \mathrm{~Pa}$ & $90 \%$ & 0.02 & $\begin{array}{c}\text { Tested at } 5.3 \mathrm{~cm} \cdot \mathrm{s}^{-1} \text { with } \\
0.3 \mu \mathrm{m} \text { DOP particles. }\end{array}$ \\
\hline Present study & $\begin{array}{c}\mathrm{C} 1(0.1 \% \\
\text { mechanical })\end{array}$ & Microfibrillated cellulose. & $55 \mathrm{~Pa}$ & $56 \%{ }^{*}$ & $0.0149^{*}$ & $\begin{array}{l}\text { Tested at } 5.3 \mathrm{~cm} \cdot \mathrm{s}^{-1} \text { with } \\
\mathrm{NaCl} \text { particles from } 10 \\
\text { to } 1000 \mathrm{~nm} .\end{array}$ \\
\hline Present study & T1 (0.1\% oxidized) & Microfibrillated cellulose. & $25 \mathrm{~Pa}$ & $46 \%{ }^{*}$ & $0.0246^{*}$ & $\begin{array}{l}\text { Tested at } 5.3 \mathrm{~cm} \cdot \mathrm{s}^{-1} \text { with } \\
\mathrm{NaCl} \text { particles from } 10 \\
\text { to } 1000 \mathrm{~nm} .\end{array}$ \\
\hline
\end{tabular}

The interaction of diffusion and interception is significant for nanofiber filters, so several models were considered to analyze both of the two phenomena. Three different parameters need to be considered in order to make a theoretical model: thickness $(Z)$, solidity $(\alpha)$ and fiber diameter $(d f)$. The thickness values of the samples were measured by means of a caliber $( \pm 0.02 \mathrm{~mm})$, while the solidity $\alpha$ was estimated according to:

$$
\alpha=\frac{W}{\rho_{f} Z}
$$

where $W$ is the mass of fibers per unit filter area (basis weight) and $\rho_{f}$ is the fiber material density [14]. Knowing $W, \rho_{f}, Z$ and measuring $\Delta P$ across the filter, the fiber diameter can be estimated from Davies' equation [14]:

$$
d_{f}^{2}=\frac{64 \mu U_{0} Z \alpha^{1.5}\left(1+56 \alpha^{3}\right)}{\Delta P}
$$

where $\mu$ is the air dynamic viscosity and $U_{0}$ the face velocity. Table 3 shows the characteristic parameters of the T1 and C1 samples.

Using this model, effective fibres diameters of $955 \mathrm{~nm}$ and $857 \mathrm{~nm}$ were determined for the T1 and C1 
samples, respectively. Most fibrils in the CNF dispersion had however diameters lower than $100 \mathrm{~nm}$. Therefore, fibrils must have agglomerated into larger structures during drying, thus giving a higher average observed fiber diameter. Figure 4 shows the $\mathrm{NaCl}$ captured particles (white dots in the upper images) on the $\mathrm{C} 1$ sample. It can be seen that particles are preferably captured on small surfaces. The observed single fibril diameter shown in the bottom picture is around $270 \mathrm{~nm}$. This value is lower than the effective fiber diameter (around $900 \mathrm{~nm}$ ), since the latter considers the whole structural complexity of the filter, which also shows the presence of sheet-like structures and crossing fibrils. Therefore, the effective fibre diameter could be considered as an equivalent fiber diameter of the whole filter material (the smaller it is, the less the fibers agglomerate) which could be regarded as the effective fiber structure of the CNF membranes.

A MATLAB code, based on Table 3 parameters, which takes into account several theoretical models [12][19], was written to fit the experimental data. Better agreement between theoretical model predicted and experimental penetration values was obtained with the Payet's model for the filter T1, produced from oxidized CNF, (Figure 5).

\begin{tabular}{|c|c|c|}
\hline Parameters & T1 sample & C1 sample \\
\hline Basis weight $\left(\mathrm{g} \cdot \mathrm{m}^{-2}\right)$ & 10 & 10 \\
\hline Fiber material density $\left(\mathrm{g} \cdot \mathrm{cm}^{-3}\right)$ & 1.5 & 1.5 \\
\hline Thickness (mm) & 2.0 & 0.7 \\
\hline Solidity & 0.003 & 0.095 \\
\hline Pressure drop at $5.3 \mathrm{~cm} \cdot \mathrm{s}^{-1}(\mathrm{~Pa})$ & 25 & 55 \\
\hline Effective fiber diameter from Davies equation (nm) & 955 & 857 \\
\hline
\end{tabular}
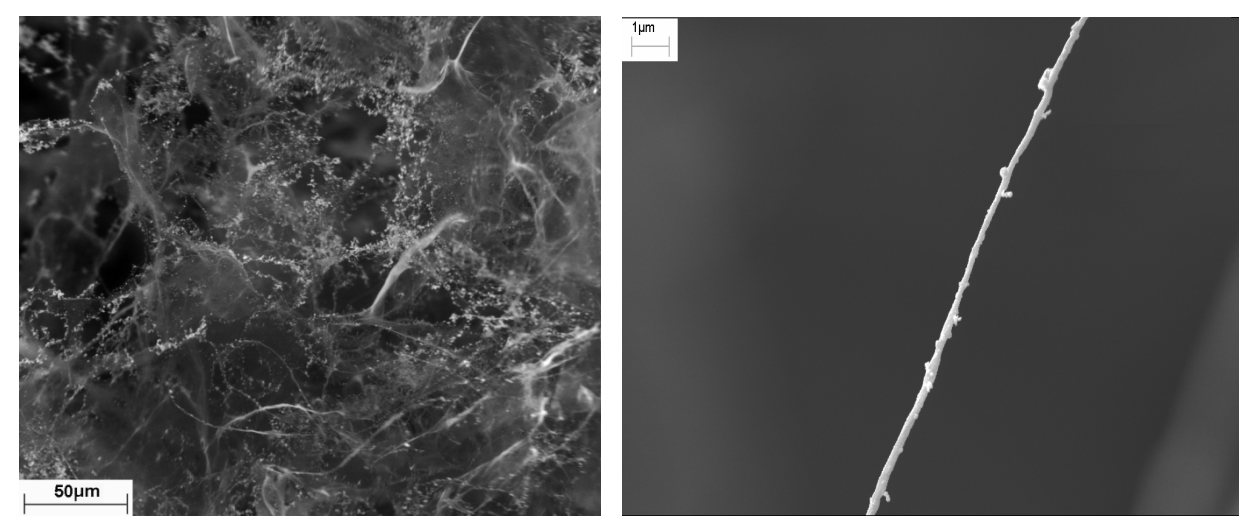

Figure 4. SEM images of filters after filtration for $\mathrm{C} 1$ sample. White dots are $\mathrm{NaCl}$ captured particles.
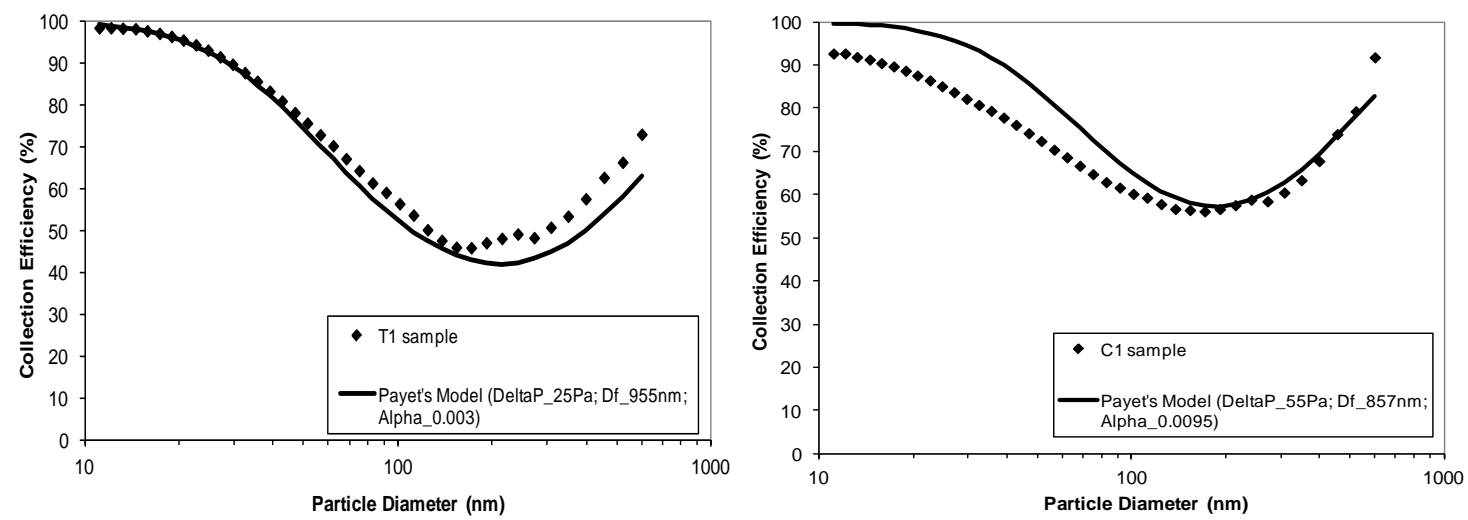

Figure 5. Experimental and model comparison for T1 and C1 samples. 


\section{Conclusions}

CNF based filters, prepared by using a freeze-drying technique, can lead to a new category of nanofiber structures, with low production costs and very compact structures, avoiding the need for extra layers to reinforce the filter strength.

The present study has explored the suitability of two different qualities of CNF as material in filters. The CNF samples were produced mechanically and with oxidation as pre-treatment giving different fibril structures. The filters were prepared by freeze drying CNF dispersions using different solid content of the initial dispersion.

Samples having solid content of $0.1 \%$ (C1 and T1) better preserved the fibrillar structure of the suspension compared to the samples having higher solid content (C2, C3, T2). The oxidized samples were more fibrillated and contained nanofibrils with relatively homogeneous fibril diameter distribution. All freeze-dried samples were rather porous, with pore diameters of roughly $100 \mu \mathrm{m}$ [20]. For $0.2 \%$ and $0.3 \%$ initial suspension solid content, the dried samples presented a mixed structure containing fibrillar and sheet-like regions.

Particle collection efficiencies were measured by means of $\mathrm{NaCl}$ particles, mainly in the nanoparticle size range, for the filters prepared from dispersions of $0.1 \%$ solid content.

CNF samples with $10 \mathrm{~g} \cdot \mathrm{m}^{-2}$ basis weight and $0.1 \%$ solid content showed QF values comparable with polymeric nanofibrous materials at the face filtration velocity of $5.3 \mathrm{~cm} \cdot \mathrm{s}^{-1}$. Both CNF qualities could be used to prepare filters with good performance; however, the filter based on oxidized CNF (T1) showed the best QF value.

For filtration applications, the computation of the effective fibre diameter, using the Davies' equation, could be used to verify the agglomeration grade of the fibrils in the filter. In addition, it can be used to predict the most particle penetration region using the Payet's theoretical model.

\section{Acknowledgements}

The work was funded by the Research Council of Norway through the grant 196119/V30.

\section{References}

[1] Dockery, D.W. and Pope, C.A. (1994) Acute Respiratory Effects of Particulate Air Pollution. Annual Review of Public Health, 15, 107-132. http://dx.doi.org/10.1146/annurev.pu.15.050194.000543

[2] Oberdörster, G., Stone, V. and Donaldson, K. (2007) Toxicology of Nanoparticles: A Historical Perspective. Nanotoxicology, 1, 2-25. http://dx.doi.org/10.1080/17435390701314761

[3] Saito, T., Nishiyama, Y., Putaux, J.L., Vignon, M. and Isogai, A. (2006) Homogeneous Suspensions of Individualized Microfibrils from TEMPO-Catalyzed Oxidation of Native Cellulose. Biomacromolecules, 7, 1687-1691. http://dx.doi.org/10.1021/bm060154s

[4] Chinga-Carrasco, G. (2011) Cellulose Fibres, Nanofibrils and Microfibrils: The Morphological Sequence of MFC Components from a Plant Physiology and Fibre Technology Point of View. Nanoscale Research Letters, 6, 417. http://dx.doi.org/10.1186/1556-276X-6-417

[5] Ishii, D., Saito, T. and Isogai, A. (2011) Viscoelastic Evaluation of Average Length of Cellulose Nanofibers Prepared by TEMPO-Mediated Oxidation. Biomacromolecules, 12, 548-550. http://dx.doi.org/10.1021/bm1013876

[6] Fukuzumi, H., Saito, T. and Isogai, A. (2013) Influence of TEMPO-Oxidized Cellulose Nanofibril Length on Film Properties. Carbohydrate Polymers, 93, 172-177. http://dx.doi.org/10.1016/j.carbpol.2012.04.069

[7] Syverud, K., Chinga-Carrasco, G., Toledo, J. and Toledo, P.G. (2011) A Comparative Study of Eucalyptus and Pinus Radiata Pulp Fibres as Raw Materials for Production of Cellulose Nanofibrils. Carbohydrate Polymers, 84, 1033-1038. http://dx.doi.org/10.1016/j.carbpol.2010.12.066

[8] May, K.R. (1973) The Collison Nebulizer: Description, Performance and Application. Journal of Aerosol Science, 4, 235-238. http://dx.doi.org/10.1016/0021-8502(73)90006-2

[9] Hinds, W.C. (1998) Aerosol Technology. 2nd Edition, Wiley-Interscience, New York.

[10] Zhang, Q., Welch, J., Park, H., Wu, C.H., Sigmund, W. and Marijnessen, J.C.M. (2010) Improvement in Nanofiber Filtration by Multiple Thin Layers of Nanofiber Mats. Journal of Aerosol Science, 41, 230-236. http://dx.doi.org/10.1016/j.jaerosci.2009.10.001

[11] Leung, W.W.F., Hung, C.H. and Yuen, P.T. (2010) Effect of Face Velocity, Nanofiber Packing Density and Thickness on Filtration Performance of Filters with Nanofibers Coated on a Substrate. Separation and Purification Technology, 71, 30-37. http://dx.doi.org/10.1016/j.seppur.2009.10.017 
[12] Hung, C.H. and Leung, W.W.F. (2011) Filtration of Nano-Aerosol Using Nanofiber Filter under Low Peclet Number and Transitional Flow Regime. Separation and Purification Technology, 79, 34-42. http://dx.doi.org/10.1016/j.seppur.2011.03.008

[13] Hassan, M.A., Yeom, B.Y., Wilkie, A., Pourdeyhimi, B. and Khan, S.A. (2013) Fabrication of Nanofiber Meltblown Membranes and Their Filtration Properties. Journal of Membrane Science, 427, 336-344. http://dx.doi.org/10.1016/j.memsci.2012.09.050

[14] Davies, C.N. (1955) The Separation of Airborne Dust and Particulates. Proceedings of the Institution of Mechanical Engineers Conference, B1, 185-213.

[15] Stechkina, I.B. and Fuchs, N.A. (1966) Studies on Fibrous Aerosol Filters-I. Calculation of Diffusional Deposition of Aerosols in Fibrous Filters. The Annals of Occupational Hygiene, 9, 59-64. http://dx.doi.org/10.1093/annhyg/9.2.59

[16] Lee, K.W. and Liu, B.Y.H. (1982) Theoretical Study of Aerosol Filtration by Fibrous Filters. Aerosol Science and Technology, 1, 147-161. http://dx.doi.org/10.1080/02786828208958584

[17] Rao, N. and Faghri, M. (1988) Computer Modeling of Aerosol Filtration by Fibrous Filters. Aerosol Science and Technology, 8, 133-156. http://dx.doi.org/10.1080/02786828808959178

[18] Payet. S., Bouland, D., Madelaine, G. and Renoux, A. (1992) Penetration and Pressure Drop of a HEPA Filter during Loading with Submicron Liquid Particles. Journal of Aerosol Science, 23, 723-735. http://dx.doi.org/10.1016/0021-8502(92)90039-X

[19] Brown, R.C. (1993) Air Filtration: An Integrated Approach to the Theory and Applications of Fibrous Filters. Pergamon Press, Oxford.

[20] Syverud, K., Kirsebom, H., Hajizadeh, S. and Chinga-Carrasco, G. (2011) Cross-Linking Cellulose Nanofibrils for Potential Elastic Cryo-Structured Gels. Nanoscale Research Letters, 6, 626. http://dx.doi.org/10.1186/1556-276X-6-626 